\title{
APROPIACIONES Y USOS DE PORTÁTILES E INTERNET EN CASTILLA LA NUEVA
}

\author{
Andrés Castellanos Melo, ${ }^{16}$ \\ Widman Said Valbuena ${ }^{17}$
}

\begin{abstract}
RESUMEN
Apoyándose en la técnica de Grupos de Discusión, los autores presentan un breve panorama sobre cómo la comunidad escolar de Castilla la Nueva (Meta), considerado primer municipio digital de Colombia, asume la tecnología en su cotidianidad y qué tipo de usos y apropiaciones de la internet y del computador portátil descansan en los enfoques tecnológicos encontrados. Asimismo, destacan las opiniones de los participantes en aspectos referidos al entendimiento, el ocio y la identidad, que encuentran en el uso de estas expresiones de la tecnología otro escenario de apropiación.

Dado el reciente ánimo de acompañar las prácticas pedagógicas con el uso efectivo de NTIC, el artículo llama la atención sobre la importancia de considerar los puntos de vista, las opiniones y las percepciones que poseen las comunidades escolares respecto a estas expresiones de la tecnología como uno de los elementos esenciales de una apuesta pedagógica propia y a tono con las exigencias del mundo contemporáneo, más aún cuando lo que se pretende, como en el caso de Colombia, es lograr avances significativos en la política de alfabetización digital.
\end{abstract}

Palabras clave: tecnología, informática, enfoques, usos del portátil e internet, grupo de discusión.

\begin{abstract}
Leaning to Discussion Grupos' technique, the authors present a brief overview about to how the school community of Castilla la Nueva (Meta, Colombia) assumes technology and what kind of uses and appropriations of the Internet and laptop rest in such technological approaches. Also, the participant's opinions highlights in matters relating to the understanding, leisure and identity, they find in that technology's expressions another stage of ownership.
\end{abstract}

Given the recent intention of the accompany teaching practices with effective use of NTIC, the paper asks to the importance of considering the views, opinions and perceptions that school communities have to respect these technology's expressions as an essential element of

16 Investigador de DIDACTEC (Didáctica de la Tecnología) de la Universidad Distrital Francisco José de Caldas. Estudiante Maestría en Política y Gestión de la Ciencia y la Tecnología de la Universidad de Buenos Aires (UBA). E-mail: andrescaste@gmail.com

17 Investigador de DIDACTEC y Magíster en Hábitat con Estudios en Vivienda de la Universidad Nacional de Colombia. E-mail: wsvalvuenab@unal.edu.co 
a gamble own teaching and in tune with the demands of the world, even more so what was intended, as in the case of Colombia, is to get significant progress in the politics of digital literacy.

Key words: information, technology, approaches, uses of laptop and internet, discussion groups.

Recibido: 5 de agosto de 2009

Aceptado: 23 de octubre de 2009

La experiencia realizada entre 2006 y 2008 en el municipio de Castilla la Nueva (Meta, Colombia), tuvo como propósito adelantar un proyecto piloto de incorporación de computadores portátiles e internet en la educación primaria y básica secundaria. ${ }^{18}$ Además del diseño de una propuesta de formación con la comunidad educativa del municipio, el grupo DIDACTEC, de la Universidad Distrital Francisco José de Caldas, realizó simultáneamente un estudio sobre las interacciones que establecen los actores escolares (directivas docentes, profesores, estudiantes y padres/madres de familia) con las NTIC y las apropiaciones que hacen de las mismas. Uno de los aspectos cruciales de esta indagación fue el rastreo de opiniones y puntos de vista en torno a la tecnología y a los usos del computador portátil, tanto en el ámbito escolar como fuera de éste.

Para tal indagación se apeló a diversas técnicas de investigación cualitativa. Una de ellas es el Grupo de Discusión, entendido como una situación discursiva a partir de la cual el grupo participante logra reorganizar el discurso social, pronunciarlo y dar cuenta de él (Canales y Peinado, 1995).

No obstante, en nuestro caso y dado el interés por rastrear también las hablas de los niños y las niñas, con los estudiantes de 3ro a 5to de primaria de la Escuela Violetas, se hizo una salvedad metodológica: Apelando a algunos elementos de cartografía social, no se le preguntó directamente al grupo por la tecnología y sus usos, sino que previamente se realizaron talleres de dibujo con otro grupo de niños y niñas de las mismas edades quienes de esta manera plasmaron sus respuestas a preguntas como “¿Qué me gusta hacer con el computador”, ¿Cuál es la clase que más me gusta?” y “¿Qué es para mí tecnología?” Posteriormente, el grupo de discusión de estudiantes de primaria observó los dibujos elaborados por sus compañeros y conversó en torno a ellos.

18 El proyecto, denominado "Prueba piloto para la incorporación del uso pedagógico de las tecnologías de la información y la comunicación, a través de la entrega de computadores portátiles a estudiantes y profesores de la escuela rural Violetas y de la Institución Educativa Castilla la Nueva", fue realizado por el grupo de investigación DIDACTEC (Didáctica de la Tecnología) de la Especialización en Educación en Tecnología de la Universidad Distrital Francisco José de Caldas y contó con el apoyo de la Alcaldía de Castilla la Nueva y del programa Computadores Para Educar, del Ministerio de Comunicaciones. En este proyecto participaron Sergio Briceño Castañeda como coordinador general, Antonio Quintana Ramírez y Ruth Molina Vásquez como investigadores, Andrés castellanos Melo y Andrea Ruiz Anzola como coordinadores temáticos, como formadores en campo Widman Said Valbuena, Edilberto Hende Puentes, Cesar Rodríguez y Adriana Guevara. Auxiliar: Andrea Jiménez González. Asesor Estadístico: Pedro Rocha. 
Dada la anterior salvedad metodológica, expondremos brevemente dos aspectos en los que las hablas recolectadas en el municipio de Castilla la Nueva alcanzan un reordenamiento del discurso social en torno a la tecnología, y más exactamente, al uso del computador y la internet. El primero tiene que ver con los enfoques sobre tecnología que se advierten en las opiniones y puntos de vista de los actores escolares participantes, y el segundo menciona brevemente los usos habituales que dichos actores le dan al computador y su correspondencia o no con el discurso que sustenta su interacción con tales aparatos.

\section{Consideraciones sobre la tecnología: artefactos y ciencia aplicada}

En los actores escolares del municipio de Castilla la Nueva coexisten dos ideas fuertes en torno a la tecnología. La primera está relacionada con aquellas opiniones que la definen en función de producciones humanas dentro de un ámbito técnico particular, es decir, aparatos, artefactos, máquinas.

Profesor 1: "Tecnología es toda máquina que apoye el trabajo del hombre".

Profesor 2: "Es como las herramientas de tipo mecánico".

En el caso de los estudiantes de sexto grado, algunos acuden a su familiaridad con los aparatos para definir la tecnología, por lo cual ésta tiene que ver con:

"Estudiante sexto: ... El horno microondas, el dispensador de agua, el lavador de losa, y todos los aparatos que hay en la casa y que necesitan corriente".

Los niños y niñas de primaria, por su parte, asocian la tecnología con un conjunto de artefactos, pero no con todos los que componen un hogar de estrato promedio, sino particularmente con electrodomésticos o aparatos electrónicos.

"Estudiante primaria: ¿Para mi qué es tecnología? Bueno, la tecnología ha avanzado mucho..., porque, es, de pasar corriente..."

De la misma manera, los niños y las niñas consideran que el monitor del computador es el elemento que concentra los demás dispositivos, transformados desde su perspectiva en componentes periféricos, como se pudo evidenciar en algunos dibujos.

Esta manera de entender la tecnología, de definirla, está relacionada con lo que Carlos Osorio (2002) denomina el enfoque instrumental o artefactual. Tal enfoque consiste en asumir que la tecnología se compone sólo de herramientas o máquinas construidas para diversas tareas y trabajos. Al mismo tiempo, dichos artefactos son el “(...) resultado del conocimiento técnico, bien sea que se trate de técnicas empíricas, en el caso de los artefactos artesanales, como de tecnologías que usa la ciencia, en el caso de los artefactos industriales" (Quintanilla, 2001, citado por Osorio, 2002, 8). 
A su vez, tal enfoque implica, según Osorio, una mirada sobre el ser humano en la que éste es influido por la máquina en diversas dimensiones de su vida social, laboral, privada y psicológica. Tal consideración sobre la relación ser humano-máquina en la vida cotidiana es compartida por algunos de los actores escolares de Castilla la Nueva, si bien a veces comporta una mirada pesimista.

Estudiante 1 primaria: "[Usar el computador portátil] por un lado es bueno y por otro lado es malo".

Dinamizador: "Tú dices que es bueno y malo ¿Por qué?...”

Estudiante 1 primaria: "Pues bueno, porque si uno se divierte, así, pero por lo malo porque uno está más pendiente así a lo, a jugar así, pero no está pendiente del amigo."

Estudiante 2 primaria: "No, pues tampoco, tampoco porque el computador se lo llevan y uno queda peleado con la mamá, que porque uno prefiere jugar con el computador en vez de comenzar a hacerse cosquillas con la mamá o algo, o con el papá."

Profesor 1: "No, pero yo sí pienso que la tecnología trata de desplazar al hombre, así sea el mismo hombre que la cree en vista de sus necesidades."

Profesor 2: “...Va a llegar el momento en que las máquinas van a estar, no al servicio de nosotros, ni nosotros al servicio de ellas. Nosotros somos esclavos de ellas".

De igual forma, la concepción artefactual o instrumentista, se tiende a creer que la tecnología empieza y termina en los aparatos, es decir, que no hay unas elaboraciones sociales, culturales y políticas previas al diseño y elaboración del artefacto.

"Dinamizador (DIZ): ¿Y para qué es la tecnología?"

"Estudiante 1 séptimo (E1S): Para aprender cosas."

"Estudiante 2 séptimo (E2S): Para saberla manejar."

"DIZ:¿Para saberla manejar?"

"E2S: Para saber qué es lo que está pasando en el mundo"

"DIZ: ¿Para informarnos?, puede ser. ¿Para qué más? ¿Tú para qué crees?”

"E3S: Para tener más avances."

El desvincular los aparatos de las ideas y los sustentos ideológicos desde los cuales fueron concebidos resulta peligroso, advierte Osorio, pues lleva a creer que los agentes sociales mejor calificados para determinar, tecnológicamente hablando, qué resulta "correcto y objetivo" para toda una comunidad, son aquellos que, justamente, están próximos al proceso de diseño y creación de artefactos: científicos, ingenieros y expertos.

Además, a partir de esa neutralidad que en apariencia caracteriza a la máquina se puede terminar por alejarla del "entramado social" desde el que fue pensada y creada, al punto de llegar a creer que la máquina sólo responde a criterios de utilidad y eficacia y cualquier 
tipo de uso que se haga de ella, bueno o malo, es responsabilidad de la sociedad, no de sus creadores o impulsores.

"Prof: El hombre está tratando de crear soluciones a partir de la tecnología. Y en algún momento, la tecnología puede sobrepasar al hombre."

"Prof: La tecnología es muy buena, siempre y cuando esté al servicio del hombre... Y pienso en lo que sucedió acá [en el municipio]: llegó la tecnología y de pronto no supimos manejar eso y hubo una invasión del espacio de clase".

El otro enfoque que se advierte en las definiciones que entregan docentes y padres/madres de familia sobre la tecnología, es el cognitivo. Siguiendo a Osorio (2002), desde este enfoque se considera que la tecnología es ciencia aplicada, y en tanto ello, la tecnología se asume como "un conjunto de reglas tecnológicas" que a su vez "serían consecuencias deducibles de las leyes científicas", por lo cual "el desarrollo tecnológico dependería de la investigación científica" (Osorio, 2002, 18).

El vincular la tecnología con cambios estructurales o funcionales, producto de la investigación científica, es una de las asociaciones más representativas del imaginario colombiano, según el análisis que hace Julia Aguirre (Edit. 2005). Para ella, esta idea emerge probablemente como repuesta al consumo de información científica centrada en los grandes logros de la industria de punta, información que constantemente circula en los medios masivos a los cuales muchas personas tienen acceso.

En efecto, para algunos actores escolares del municipio estudiado, la tecnología es algo mucho más elaborado que los electrodomésticos y está presente en otra clase de productos surgidos, en no pocos casos, de la actividad científica:

Prof: "Yo tengo la idea de que tecnología es aplicar el conocimiento para la construcción de algo"

Prof: "Es la materialización de los pensamientos avanzados".

Prof. 2: "Para tecnología... lo que entiendo es producción".

Prof. 3: "Planificación".

Dinamizador (Diz): "En general, ¿qué es la tecnología?”

Prof. 1: "Es como un pensamiento avanzado".

Diz: "Es una idea diferente a lo que plantean los otros profesores. ¿Hay alguna otra idea de que es eso, o están en desacuerdo?".

Prof. 1: "Es un pensamiento avanzado, porque el hombre va haciendo lo que es necesario para él".

Prof. 2: "Pero hay otros pensamientos avanzados y no todos implican tecnología".

Diz: "Un ejemplo, profe" (sic).

Prof. 1: “... El hecho de que yo me proyecte sobre lo que pueda suceder en el desarrollo de la humanidad y no utilice herramientas, me parece que eso no es tecnología”. 
En los estudiantes de séptimo grado también se advierten ideas semejantes:

Estudiante 1 Séptimo: "La tecnología es como la evolución, como por lo menos como lo dice él, que antes eran grandes y ya lo han venido... como a la comodidad de poderlo tener en cualquier parte, y de estar en contacto con el aparato."

Estudiante 2 Séptimo: "Son avances, ¿si?, la tecnología son algo nuevo. E ideas y propuestas nuevas... Porque, por lo menos la rueda ha venido evolucionando. Y como algunas cosas también han venido evolucionando. Y la tecnología se basa en eso, en la innovación de las cosas que ya se han hecho."

Y los estudiantes de sexto grado, por su parte, se aproximan a la idea de ciencia aplicada al considerar que es a merced de la tecnología que el ser humano apropia los elementos con que lo dota la naturaleza en tanto la transforma.

Estudiante sexto: "Porque, mire, si no fuera algo natural, ¿cómo hacen para hacer todo eso? Porque para hacer algo uno necesita materiales y todo eso..."

Por lo mismo, no sólo los computadores portátiles y otros aparatos se consideran tecnología. También abarca materiales, elementos, sustancias que nos resultan muy familiares y sobre las cuales no solemos reparar con frecuencia, por ejemplo:

Estudiante Sexto: “... El jabón está hecho con cosas naturales; pero si se combina todo lo natural, el cemento está hecho con algo natural".

Este enfoque sobre la tecnología presenta, al igual que el anterior, algunos riesgos. El primero consiste en pensar que las teorías con que trabaja el tecnólogo son menos complejas que las de la ciencia, cuando "la tecnología moderna descansa en un alto nivel de complejidad, a partir de la automatización” (Osorio, 2002, 26). El segundo, relacionado con la consideración de Julia Aguirre (Edit. 2005) respecto a la noción de tecnología que circula en los medios masivos de comunicación, estriba en reducir la relación entre ciencia y tecnología a ciencia aplicada, cuando se trata de una relación mucho más compleja, de "subculturas simétricamente interdependientes"(Osorio, 2002, 30). Y por último, tiene que ver con considerar que "a más ciencia, más tecnología, y, por consiguiente, tendremos más progreso económico, lo que nos trae más progreso social"' (29).

Desde tal mirada se puede llegar a creer que la sola incorporación de aparatos y de otras aplicaciones tecnológicas de la ciencia transformará la sociedad, permitiendo su desarrollo, alcanzando así los peldaños más altos del progreso y, por tanto, logrando satisfacer las necesidades de toda una comunidad. Se sabe perfectamente que esta ecuación lineal ha fallado y que no precisamente las expresiones de la ciencia aplicada favorecen los intereses 
mayoritarios de una sociedad, ni los satisfactores ${ }^{19}$ que produce la ciencia necesariamente responden a las necesidades de las comunidades.

En otras palabras, el enfoque cognitivo puede derivar en una mirada muy estrecha sobre la tecnología y sobre el lugar que ha de ocupar en el ámbito educativo. Las ideas de progreso, bienestar y eficiencia que están atadas al concepto de "ciencia aplicada", soslayan o posponen la discusión sobre algunas problemáticas sociopolíticas, económicas y culturales a partir de las cuales las comunidades se reconocen y avanzan, construyen un sentido colectivo sobre su presente y su porvenir.

\section{Usos del computador portátil e internet: ocio, identidad, entendimiento}

Además de los usuarios directos con que contó el proyecto (estudiantes de la Escuela Rural Violetas, estudiantes de sexto grado del Colegio Castilla la Nueva, así como sus profesores), poco a poco fueron surgiendo algunos usuarios indirectos: madres y padres de familia, hermanos, primos, tíos e incluso vecinos. Esta situación se produjo gracias a dos condiciones importantes. La primera es la característica de portátil del computador, la cual permitió que los estudiantes llevaran los equipos a sus casas y establecieran con aquél una interacción mucho más personal. Y la segunda es que gracias al servicio público gratuito de Internet inalámbrico (brindado por el municipio), era posible el acceso a la red desde algunos barrios y veredas, o desde lugares públicos, como parques y plazas.

Así, cuando se conversó con profesores y familiares de los estudiantes sobre los usos que ellos daban al portátil y a la Internet, no pocas veces sus hablas se centraron más en los usos de los niños y de las niñas que en lo que ellos mismos hacían con el aparato.

\section{Desde las hablas de los adultos}

Los docentes, por ejemplo, distinguen entre unos usos adecuados dentro del contexto escolar y que están asociados con la necesidad de entendimiento, y otros inadecuados, asociados a la necesidad de ocio. ${ }^{20} \mathrm{Al}$ decir de los maestros, en sus estudiantes han primado los segundos.

19 De acuerdo con Max-Neef y otros (1993), un satisfactor es aquello que permite responder a una necesidad. Sin embargo, históricamente, necesidad y satisfactor se han confundido. Así: "alimentación y abrigo no deben considerarse como necesidades, sino como satisfactores de la necesidad fundamental de Subsistencia", por ejemplo. Ver MAX- NEEF, Manfred, ELIZALDE, Antonio, y HOPPENHAYN, Martin, "Desarrollo a escala humana. Conceptos, aplicaciones y algunas reflexiones". Editorial Nordan-Comunidad, Montevideo. 1993 en: http://www.fh.userena.cl/educacion/maxneef.htm. Última visita: febrero 14 de 2008

20 Dentro de esta investigación se encontró que el uso de computadores portátiles e internet responde complejamente a cuatro necesidades existenciales de las que expone Max Neff en su teoría de desarrollo a escala humana, son estas: el ocio, la identidad, el entendimiento y el afecto. Al respecto ver: Valbuena W. (2009) Reset y F5, ¿son las tic una necesidad de la tecnología actual? Revista de investigaciones UNAD- volumen $8, \mathrm{~N}^{\circ} 1$, pág 171 , en: http://www.unad.edu.co/revista_investigacion/images/Volumen8N1/10resetf5.pdf 
Prof. "Yo lo único que digo es que para los estudiantes, en este momento, el computador, más que una herramienta de estudio, es lo que les sirve para distraerse. El computador es para jugar, para escuchar música y para estar en el Messenger. Para ellos el computador está muy lejos de pensar (sic) que les sirve para estudiar. O, "Bueno, sí, me sirve”, pero no para eso."

Tal distinción entre usos adecuados o inadecuados depende en gran medida del momento y del lugar en que se utiliza el portátil. Incluso a veces el uso puede ser el mismo, pero tanto el momento como el lugar en donde se realice definen si su empleo es apropiado o inapropiado, educativo u ocioso para utilizar las categorías locales.

Prof. “... yo conseguí como unos 80 programas de juegos... [pero] en las casas de los niños no coge Internet, entonces a mi me pareció muy curioso al comienzo del proyecto meterle a cada equipo sus 80 juegos, independiente de que tengan Internet o no, pues ellos están pegados a los juegos. Pero es que hay muchos puntos de vista frente a este proyecto".

De ahí que, incluso tratándose de juegos con fines educativos, para algunos(as) docentes aquéllos pueden resultar nocivos, permisivos, si la interacción a través del computador portátil se sucede en las horas de clase e interrumpe los ritmos de trabajo y descanso habituales de la escuela.

Prof. “... En el caso de [la Escuela] Violetas pasó relativamente lo del Colegio [Castilla], los niños están demasiado en el cuento del computador y ellos no quieren saber de nada más, ellos no quieren clase de Educación Física, no quieren recreo porque el recreo ya no es una pelota sino juegos.com: Tanto así que se volvió una obsesión".

Tales situaciones, comentadas por una docente, llevan a pensar que los videojuegos generan una introversión en el niño que lo conduce a desplazar en importancia a otras actividades que habitualmente eran de su interés. Al respecto, Roberto Balaguer (2002) dice que "si bien por un lado esto [La introversión] es observable en algunos casos límite, en la mayoría vemos cómo la información "navegada" o el truco aprendido para superar determinada pantalla de un videojuego, es material socializante (Balaguer, 2002, 36).

"Los niños, agrega Balaguer, comentan e intercambian acerca de sus nuevos descubrimientos con los demás, transformando esta actividad en una actividad socializante, similar a la que llevan a cabo los adultos, sea el tema Gran Hermano o un artículo de periódico o semanario. Este aspecto se encuentra también relacionado con lo que Marsha Kinder denomina un "supersistema", es decir, todo el entorno que se crea alrededor de los personajes de los videojuegos que trascienden la pantalla" (Levis, 1997, citado por Balaguer, 2002, 37).

Pero los estudiantes no sólo intercambian su saber y experiencia sobre juegos. En opinión de algunos padres y madres de familia, el chat ha ido cobrando importancia entre los estudiantes de sexto grado y primaria. Al respecto, en otro artículo Balaguer (2005) nos recuerda que: "Los jóvenes chateando interactúan como si hablaran entre ellos y no como si se estuvieran 
escribiendo mensajes. Esto es válido tanto para el chat como para la mensajería instantánea. La sintaxis, el estilo, son bien cercanos a la oralidad dentro de ese espacio psicosocial, que es un espacio básicamente de encuentro" (Balaguer, 2005, 6).

Madre de familia: "Pues allá, prácticamente como no tengo puertas así... Aunque a veces ella se me va para el parque pero yo voy y le echo un vistazo. Una vez llegué y estaba chateando con otro sardino (sic) y ella ríase y hable. Pero ella no me había visto, pero cuando me vio, claro, se asustó".

Investigador (Inv.) “¿Tu has chateado?, ¿Por qué?”

Estudiante (Est.) "Sí, pero con otros computadores, cuando no tenía el mío. Pero hablando con gente de aquí mismo, del internado".

Inv. “¿Para qué se ponen a chatear?”

Est. "Porque hay cosas que uno no puede hablar personalmente, ¿si me entiende? Entonces uno por el Chat, pues, no le da tanta pena, pero sí escribe las cosas que uno necesita hablar con las personas".

Inv. “¿Como sobre qué?, ¿Qué temas son los que da pena así, hablar así como estamos nosotros y qué es mejor hablar por Chat?"

Est. "Pues, yo cómo le dijera..."

Est 2. "Pues sobre el noviazgo".

Est. "Más que todo cuando estoy brava (sic) con alguien o otra persona conmigo. Entonces ahí es donde yo le digo cosas que, ¿si me entiende?, que él debería saber que yo siento de esa persona y todo". (Entrevista a estudiantes).

Lo anterior también obedece a que ciertos contenidos que intenta transmitir la Escuela entran en conflicto con otros contenidos a los que acceden niños y jóvenes en su relación con los medios masivos y otras expresiones de la tecnología. En efecto, la cultura informática escolar "entra, además, en conflicto con la cultura comunicativo/afectiva de los estudiantes, fuertemente influida por los medios y nuevas tecnologías. La primera, centrada en prácticas frontales de clase, en la repetición y mecanización de tareas, en el libro o el texto como única guía. Y la segunda, caracterizada principalmente por las nuevas posibilidades comunicativas, expresivas y lúdicas de las nuevas tecnologías" (Rueda O., 2001, p. 71).

De ahí que se pueda afirmar que no ha sido propiamente la llegada del computador portátil lo que ha generado esta disputa entre prácticas adecuadas e inadecuadas, entre "buenos"y "malos" usos de la tecnología. El campo de disputa ya estaba planteado, sólo que la introducción de un aparato como el computador portátil y la posibilidad de un uso permanente de Internet han 
agregado un nuevo round a lo que Jorge Huergo (2001, p. 92) llama las "pugnas culturales por el sentido" entre la cultura mediática y la cultura escolar.

\section{Desde las hablas de los niños y las niñas}

Tanto los niños y las niñas de grado sexto del colegio Castilla la Nueva, como los de primaria de la Escuela Violetas sintetizan el uso más generalizado del computador portátil en los videojuegos. No sólo ha resultado ser para ellos un motivo de búsqueda y desarrollo de habilidades mecánicas y mentales, sino, como ya lo ha mencionado Balaguer, un material socializante. Una estudiante, por ejemplo, cuenta lo siguiente respecto al videojuego "Arma tu muñeca":

"Es un juego que se llama, "arma tu muñeca", y entonces uno llega y le coloca la cabecita, la camisa, la falda, bueno todo, y el pelo, todo, los zapatos, todo eso lo tiene uno que colocar y con la amiga, la amiga tiene que estar al lado y uno viste la otra amiga, y entonces luego ella llega y al final le dice game over (sic) si le queda mal. Y si le quedó bien, le dice felicitación shrek (sic), bueno, algo así. O de pronto le dicen, eh, [obtuviste] "Cien puntos" o le dan el puntaje que uno ha ido... Y si le da más de cien, entonces, pues "¡Muy bien, un duro, ganaste!”

Pero además de una búsqueda de satisfactores de ocio, en los estudiantes se advierten otras preocupaciones e intereses vinculados con la identidad, en la medida en que este tipo de juegos dan la posibilidad a niños y niñas de ir conformando un territorio dotado de significados y sentidos que, por una parte, les permite diferenciarse de sus demás pares, pero por otra, les hace partícipes de un grupo o colectivo. No olvidemos que la identidad fluctúa constantemente entre lo que soy, lo que fui y lo que seré, entre lo que comparto con otros y lo que me diferencia de éstos. ${ }^{21}$

En efecto la identidad es otra de las necesidades existenciales cuyos posibles satisfactores se construyen en la relación que los individuos establecen con los artefactos. En la experiencia con los niños de Castilla la Nueva el satisfactor más evidente en la relación individuoartefacto es la comunicación asistida principalmente por productos culturales informáticos como la música digital, los juegos interactivos, los espacios de comunidades virtuales, y las imágenes. Estas últimas sirven, además, como íconos o marcas de apropiación simbólica de un nuevo "territorio", como se observa en las imágenes 1 y 2.

21 Al respecto, Patricia Vaca y Diego Romero, parafraseando a Berger y Luckman, afirman que “... el niño no aprehende por sí solo los significados, sino que éstos son interiorizados en el proceso de socialización, a través del cual el niño asume el mundo del otro y de esta manera va construyendo un esquema general de significados que finalmente constituye una cosmovisión". VACA Patricia y ROMERO Diego (2007) "construcción de significados frente a los contenidos violentos de los videojuegos en niños de 11 a 14 años". Acta colombiana de psicología 10, Universidad de la Sabana, Bogotá. Pp. 35-48. 

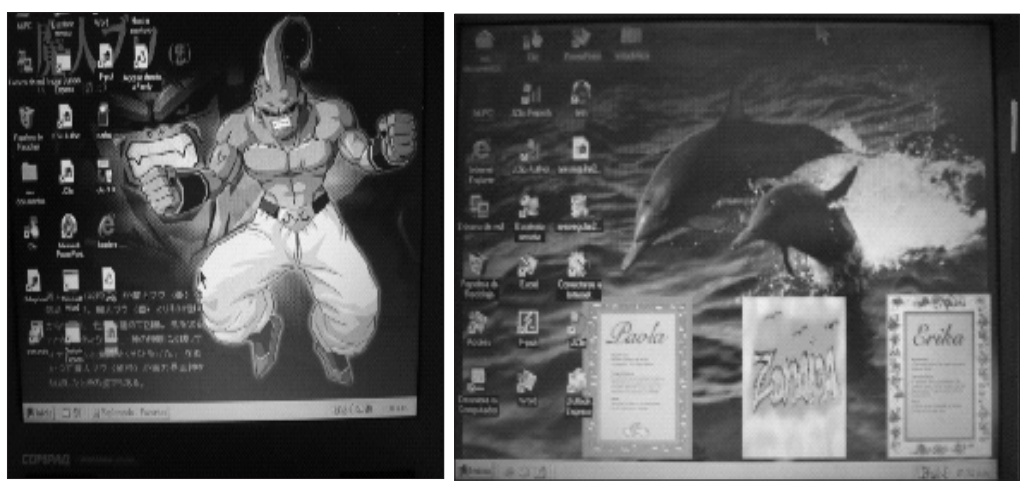

Imágenes 1 y 2

\section{Apropiación del territorio digital, por medio de la personalización}

Más allá de un análisis semiótico exhaustivo, en las imágenes se advierte que internet y el uso del computador personal ofrecen un nuevo escenario de elección y exhibición de productos que sirven de marcas, huellas, incluso de mojones, al territorio identitario tanto de los y las niñas, como de las y los jóvenes. Resulta comprensible entonces que aunque la búsqueda de satisfactores se produzca en espacios de la intimidad o lugares que son compartidos con los pares más cercanos, su publicación o su socialización tenga lugar en la escuela, uno de los contextos cruciales en tales edades para el desenvolvimiento y cultivo de la identidad.

Pero contrario a lo que opinan algunos de los adultos, el juego no ocupa toda la atención de los estudiantes en su búsqueda de satisfactores. También es posible rastrear otros usos del portátil y la internet que -aunque tímidamente- dan alguna respuesta a la necesidad de entendimiento, siendo ésta, quizá, la necesidad más relacionada con el aprendizaje. Veamos brevemente qué dicen al respecto algunos estudiantes:

Estudiante primaria: "Es que uno también puede encontrar información, juegos, todo lo que uno quiera buscar en gugli $\neg[$ google $]$.. y al otro día ya llega con la tarea a mostrársela a la profesora."

Dinamizador: "Y en tu caso, ¿para qué otras cosas usas el computador?

Estudiante sexto: “... Para aprender a hacer consultas y trabajar lo mejor, o también para la búsqueda de información, para tareas, por Google, ya uno sabe que [en la red] le dan casi todo lo que uno busca."

Aunque no es posible afirmar que la mera búsqueda de información es en sí un satisfactor real de la necesidad de entendimiento, sí se le puede considerar una primera instancia. Es muy fácil caer en el "Ctrl $+\mathrm{c}, \mathrm{Ctrl}+\mathrm{v}$ " cuando se pide una información puntual. Sin embargo, igualmente 
es claro que la información se puede transformar en conocimiento cuando se procesa en el aprendizaje, cuando se aísla por medio del análisis, se articula gracias al ejercicio de síntesis para su posterior interpretación y luego es apropiada como recurso para resolver situaciones. Son estas, básicamente, las acciones que se le piden a un individuo para que la información que recibe deje de ser mera información y se transforme en conocimiento, de modo que responda a su necesidad existencial de entendimiento del mundo.

Novak (1988) explica que el aprendizaje significativo es aquel proceso que permite la transformación de la estructura conceptual del individuo. Esta transformación se produce gracias a que una nueva información es fácilmente anclada a la estructura previa que posee el aprendiz, alimentando esta estructura o trasformándola sustancialmente, todo depende del tipo de información y de la forma en que ésta se articula a la estructura del individuo. Pero este anclaje no es un proceso mecánico de entrada de información y ensamblaje directo. Para que este proceso se realice, agrega Novak, deben existir dos condiciones importantes. La primera es que la nueva información sea potencialmente significativa y la segunda, que el individuo muestre una actitud dispuesta para el aprendizaje, lo cual sugiere acciones que permitan empalmar esta nueva información a la estructura, convirtiéndola en parte de un concepto más complejo, es decir, en conocimiento.

Al realizar este proceso se puede afirmar que se obtiene respuesta al entendimiento por medio del aprendizaje. Por tal razón es importante entender el aprendizaje como aquel satisfactor que se ocupa del tratamiento efectivo de la información. No se puede negar, por tanto, que artefactos como el computador e Internet poseen el potencial que permite este tratamiento, aunque para responder al entendimiento es el individuo quien debe procesar la información y no los aparatos, ya que estos son únicamente elementos mediadores entre la necesidad de entendimiento y satisfactores como la comunicación, el juego o el aprendizaje.

\section{CONCLUSIÓN}

Dentro de la comunidad educativa de Castilla la Nueva se encuentran, principalmente, dos enfoques característicos en cuanto a lo que los actores escolares consideran que es la tecnología. Uno de estos es entenderla como el conjunto de artefactos y productos elaborados por la humanidad y con los cuales interactúan cotidianamente (enfoque artefactual o instrumental). El otro, un tanto menos visible aunque no por ello menos importante, denominado enfoque cognitivo, en el cual reside una concepción de la tecnología como un producto derivado de la actividad científica, lo que bien puede animar cierto determinismo científico respecto a la producción tecnológica atribuido, probablemente, a la actual imagen favorable que posee la ciencia en las sociedades contemporáneas.

Una segunda conclusión es que la necesidad que recibe más atención por medio del uso de artefactos como el computador y la Internet es el ocio. En cuanto a la necesidad de entendimiento, ha quedado, en opinión de docentes y padres/madres de familia, relegada a un segundo plano, pese a la indudable capacidad que poseen estos medios para cualificar satisfactores del entendimiento como el juego o como la comunicación. También se advierte, 
aunque no de forma contundente, que niños, niñas y jóvenes del municipio acuden a ambas actividades como posibilidades de construcción de un territorio identitario estampando en los aparatos marcas y mojones que constituyen, en la interacción, "limites" territoriales.

Por último, consideramos importante para iniciativas similares como la realizada en Castilla la Nueva no sólo garantizar una incorporación efectiva de equipos y una adecuada orientación pedagógica sobre su uso, sino también explorar y conocer las percepciones y opiniones que sobre los artefactos y sus usos posee la población participante.

Como se pudo advertir en la presente experiencia, la idea de la tecnología como conjunto de aparatos que son utilizados principalmente para satisfacer la necesidad de ocio puede llegar a impedir que los mismos usuarios encuentren o exploren otras posibilidades con los mismos artefactos, impide que los vinculen a procesos cruciales en torno a la identidad, a la construcción de sentido y, desde luego, a la construcción de comunidad. Así, una iniciativa formativa, pedagógica, de incorporación de expresiones de la tecnología al ámbito escolar y al cotidiano de una comunidad que empieza a familiarizarse con ellas, nos parece, no puede pasar por alto esta reflexión y, por el contrario, en lo posible ha de orientar a la comunidad en la construcción de respuestas satisfactorias para ella.

\section{REFERENCIAS BIBLIOGRÁFICAS}

AGUIRRE, Julia (Ed). ( 2005), La percepción que tienen los colombianos sobre la ciencia y la tecnología Bogotá: Ediciones Instituto Colombiano Para El Desarrollo De La Ciencia Y La Tecnología Francisco José De Caldas, Colciencias.

BALAGUER P., Roberto, (2008, 14 de febrero), "Videojuegos, Internet, Infancia y Adolescencia del nuevo milenio". Fuente original: Revista KAIROS (en red)- Año 6 No. 10, 2do. Semestre 2002. Recuperado en: http://www.cibersociedad.net/archivo/articulo. php?art $=6$

, (2008, 14 de febrero), "El chat y el Messenger: instrumentos de entrenamiento en comunicación para tiempos de incertidumbre y baja atención". Ponencia presentada en el marco de las VIII Jornadas de AIDEP, The British Schools, Montevideo, 2005. Recuperado en :http://www.cibersociedad.net/archivo/articulo. php?art=209

CANALES, Manuel y PEINADO, Anselmo (1995): “Grupos de discusión”. En DELGADO, J. Manuel y Juan GUTIÉRREZ (coords.); Métodos y técnicas cualitativas de investigación en ciencias sociales. Madrid: Editorial Síntesis.

HUERGO, Jorge, (2001), "Desbordes y conflictos entre la cultura escolar y la cultura mediática" en Revista Nómadas, Departamento de Investigaciones Universidad Central, $15,88-100$. 
MAX- NEEF, Manfred, ELIZALDE, Antonio, y HOPPENHAYN, Martin, (2008, 29 de enero) "Desarrollo a escala humana. Conceptos, aplicaciones y algunas reflexiones". Recuperado en: http://www.fh.userena.cl/educacion/maxneef.htm Última visita: mayo de 2008.

NOVAK, J. D. y GOWIN, D.B. (1988) "Aprendiendo a aprender". Barcelona: Ed. Martínez Roca.

OSORIO, Carlos (2007, 13 de diciembre) "Enfoques sobre la tecnología" en Revista Iberoamericana de Ciencia, Tecnología, Sociedad e Innovación, No.2 enero-abril de 2002. Recuperado en: http://www.oei.es/revistactsi/numero2/osorio.htm Última visita: Enero 17 de 2009.

RUEDA, Rocío, (2001), ¿Tecnoutopía en la escuela? La necesidad de una pedagogía crítica” en Revista Nómadas, Departamento de Investigaciones Universidad Central, 15, 66-75.

VACA Patricia y ROMERO Diego (2008, 27 de febrero). "Construcción de significados frente a los contenidos violentos de los videojuegos en niños de 11 a 14 años". Acta colombiana de Psicología, Bogotá: Universidad de La Sabana, 10 35-48.

VALBUENA Widman. (2009). "Reset y F5, ¿son las tic una necesidad de la tecnología actual?”. Revista de Investigaciones UNAD, Vol. 8. №. 1. Pág. 171. 